\title{
How ocean stirring affects climate
}

\author{
The Great Ocean Conveyor: Discovering the \\ Trigger for Abrupt Climate Change \\ by Wally Broecker \\ Princeton University Press: 2010 \\ 172 pp. $\$ 27.95, £ 19.95$
}

Wally Broecker is one of the great pioneers of palaeoclimatology, the study of past climate changes in Earth's history. He introduced the term global warming and, in the 1980s, proposed that the global ocean-circulation system, which he dubbed the Great Ocean Conveyor, tends to 'flip-flop' between radically different yet stable states. The switching on and off of this overturning motion of the ocean waters, by which warm water flows northwards in the Atlantic and returns southwards in the cold abyss, could explain abrupt climate shifts during the last ice age. This period, which lasted from about 110,000 years ago until around 10,000 years ago, saw dramatic regional temperature changes in the order of $10^{\circ} \mathrm{C}$ that developed in a few decades but lasted for centuries.

In The Great Ocean Conveyor, Broecker offers a history of his thinking on the topic. Relating his breakthroughs and setbacks, he portrays science as a "continual struggle to understand more fully and more accurately how the world really works". He describes the key data sets of palaeoclimate - drawn from ice sheets, ocean sediments, ancient corals or cave stalagmites - and the detective work of deriving climate information from them. Many historical anecdotes are included, such as the harrowing story of the Russian scientists who retrieved the Vostok ice core from Antarctica: after their generator broke down, they "survived by huddling in an ice cave heated only by candles".

The book is strong in describing work based on palaeoclimatic proxy data - indirect indicators of past climate, such as the isotopes found in microscopic sea shells or the gases in air bubbles found in ancient ice. It is weaker on climate modelling. Broecker dismisses models as having had "little predictive success". Yet models are not intended to predict past climate events; rather, they are a valid tool for quantitatively testing hypotheses about the mechanisms of climate change.

Central to the book is the explanation of abrupt glacial climate changes in terms of the Atlantic Ocean Conveyor switching on and off. These are manifested as sudden warmings, known as Dansgaard-Oeschger events, and as occurrences of iceberg armadas associated with cooling, called Heinrich events. Broecker leads his readers to the puzzle of why the two types of

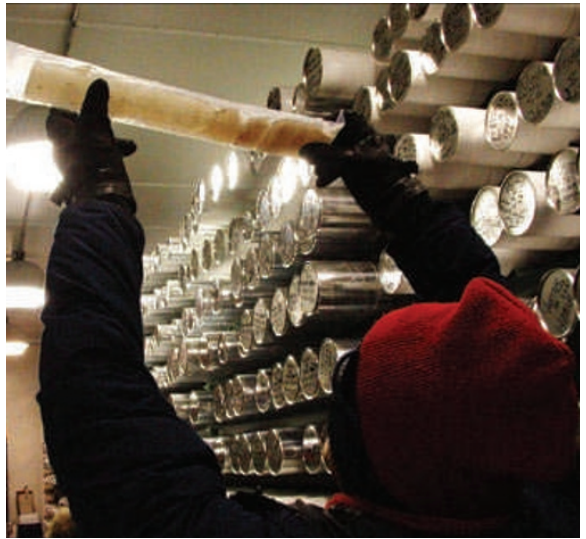

Russian scientists survived with only candles for warmth while retrieving this Antarctic ice core.

abrupt event leave different geographic traces in palaeoclimatic records. Extending his idea of ocean-conveyor switching to include shifts in latitude of the Atlantic overturning circulation would offer a solution to this problem - but strangely, Broecker does not discuss it.

Warm Atlantic waters in the North Atlantic Current - the extension of the Gulf Stream may either stop south of Iceland or push north into the Nordic seas. The latter can explain the Dansgaard-Oeschger warmings. This idea, proposed by me in 1994 (see Nature 372, 82-85) and popularized by Broecker in Scientific American in 1995, has been much elaborated, notably by Andrey Ganopolski at the Potsdam Institute for Climate Impact Research, Germany. Now widely accepted, the theory is noted as an explanation for such warming events in the most recent report of the Intergovernmental Panel on Climate Change. It would have been interesting to hear Broecker's views on this development of his original concept.

Broecker ends his book with the current geological age, the Anthropocene. In a 1975 Science paper entitled 'Are we on the brink of a pronounced global warming?', he correctly predicted "that the present cooling trend will, within a decade or so, give way to a pronounced warming induced by carbon dioxide", and that "by early in the next century, $\left[\mathrm{CO}_{2}\right]$ will have driven the mean planetary temperature beyond the limits experienced during the last 1,000 years". He also foresaw a mean global temperature rise of $0.8^{\circ} \mathrm{C}$ over the twentieth century. Broecker concludes that climate shifts induced by ocean conveyor flip-flops are relevant, but a more immediate risk is drought - the palaeoclimatic records show evidence of many major and sometimes abrupt changes in rainfall patterns. "Climate is an angry beast," he remarks.

Earth's history tells us that climate has often responded to forcing in a sensitive, nonlinear and unpredictable way. It is likely to do so again now that we are pushing it away from equilibrium with our greenhouse gases. As we struggle to understand how close we are to the climate system's tipping points, it is wise not to push too hard.

Stefan Rahmstorf is professor of physics of the oceans at the Potsdam Institute for Climate Impact Research, D-14412 Potsdam, Germany, and co-author of The Climate Crisis with David Archer.

\section{Lost curve hits a nerve}

\section{Die Helmholtz Kurven: auf der Spur der verlorenen Zeit (The Helmholtz Curves: In Search of Lost Time) \\ by Henning Schmidgen \\ Merve: 2009. 270 pp. €20}

Hermann von Helmholtz (1821-1894) was a towering figure of the European Enlightenment, a physiologist and accomplished draftsman with the soul of a Prussian physicist. He conducted his research with rigorous mathematical precision, investigating his biological preparations by adapting whichever industrialrevolution technologies he saw fit.

His formidable set of skills, combined with an equally formidable intelligence, enabled him in 1850 to work out the speed of signal propagation in nerves - then a fundamental problem in the highly competitive field of nerve and muscle physiology. However, his contemporaries did not believe him.

Using the physiologist's favourite preparation of a large frog muscle still attached to its long nerve, he had declared the speed of conductance to be around 27 metres per second. This seemed improbably slow to a sceptical scientific community by now familiar with the speeds of light and sound. So Helmholtz developed yet another skill: science communication. He decided to generate visible proof of his claim, using curves that were drawn by the contracting frog muscle itself after electrical stimulation of its nerve.

Those original curves were never published and were believed to have been lost. But last summer, German science historian Henning 